\title{
Organic Dye Design Tools for Efficient Photocurrent Generation in Dye-Sensitized Solar Cells: Exciton Binding Energy and Electron Acceptors
}

\author{
Bong-Gi Kim, Chang-Gua Zhen, Eun Jeong Jeong, John Kieffer, * and Jinsang Kim*
}

The relationship between the exciton binding energies of several pure organic dyes and their chemical structures is explored using density functional theory calculations in order to optimize the molecular design in terms of the lightto-electric energy-conversion efficiency in dye-sensitized solar cell devices. Comparing calculations with measurements reveals that the exciton binding energy and quantum yield are inversely correlated, implying that dyes with lower exciton binding energy produce electric current from the absorbed photons more efficiently. When a strong electron-accepting moiety is inserted in the middle of the dye framework, the light-to-electric energy-conversion behavior significantly deteriorates. As verified by electronic-structure calculations, this is likely due to electron localization near the electron-deficient group. The combined computational and experimental design approach provides insight into the functioning of organic photosensitizing dyes for solar-cell applications. This is exemplified by the development of a novel, allorganic dye (EB-01) exhibiting a power conversion efficiency of over $9 \%$. chemical stability. ${ }^{[3]}$ However, the limited availability of $\mathrm{Ru}$ as a noble metal hampers its wide application. Accordingly, metal-free organic sensitizers have been a research topic of recent interest. To substitute classical $\mathrm{Ru}$ complexes with all organics has several advantages, such as the infinite flexibility in molecular design, the larger molar extinction coefficient and the elimination of environmental issues. Many efficient organic dyes for DSSCs containing triphenylamine, ${ }^{[11-13]}$ coumarin, ${ }^{[14,15]}$ merocyanine, ${ }^{[16,17]}$ indoline, ${ }^{[18,19]}$ fluorene, ${ }^{[20,21]}$ or carbazole ${ }^{[22,23]}$ moieties have been developed, yielding efficiencies in the range of 4-9\%.

However, for organic dyes to be an efficient sensitizer several disadvantages have to be overcome. All-organic dyes generally exhibit a shorter exciton lifetime in their excited states than in metal complexes, ${ }^{[24]}$

\section{Introduction}

In recent years, dye-sensitized solar cells (DSSCs) have drawn significant interest as a promising cost-effective alternative to conventional silicon-based solar cells. ${ }^{[1-10]}$ Photosensitizing dyes critically affect the solar-to-electric power conversion efficiency of DSSCs, and various types of dyes have been investigated to improve overall device performance. Especially, ruthenium $(\mathrm{Ru})$ cordinated dyes exhibit more than $10 \%$ power conversion efficiency due to their broad absorption via metal-to-ligand charge transfer (MLCT), the longer exciton life-time and their long-term

B.-G. Kim, Prof. J. Kim

Macromolecular Science and Engineering

University of Michigan

Ann Arbor, MI 48109, USA

E-mail: jinsang@umich.edu

Dr. C.-G. Zhen, Dr. E. J. Jeong, Prof. J. Kieffer, Prof. J. Kim

Department of Material Science and Engineering

University of Michigan

Ann Arbor, MI 48109, USA

E-mail:kieffer@umich.edu

Prof. J. Kim

Chemical Engineering

University of Michigan

Ann Arbor, MI 48109, USA

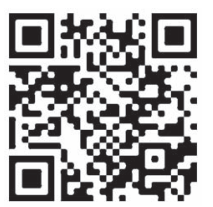

DOI: 10.1002/adfm.201101961 display aggregation-induced self-quenching[25] and have a relatively narrow absorption band in the visible region, ${ }^{[26]}$ which limit their light-harvesting efficiency. To improve this efficiency, dyes have been designed with a specific band-gap to match the maximum photon flux region $(600-700 \mathrm{~nm})$ by introducing electron donor-acceptor structures into the dye framework. However, unexpectedly they show a low power conversion efficiency, mostly because they yield a lower photocurrent than similarly structured dyes without electron-withdrawing acceptor groups. ${ }^{[11]}$ Hence, a better understanding of the photocurrent generation properties of organic dyes is needed to devise a reliable dyedesign tool, and eventually develop more efficient organic dyes for DSSCs. Since DSSCs are one of the excitonic solar cells, the generated photocurrent is inextricably related to the charge dissociation energy, which is quantitatively proportional to the exciton binding energy (EBE) of the dye. In this contribution, we investigate the relationship between the photosensitive dye's EBE and its photocurrent generation behavior. To this end, the effect of functionalization of dye molecules with electron-acceptor moieties on DSSC efficiency was investigated systematically by means of density functional theory (DFT) calculations.

\section{Results and Discussion}

To analyze the relationship between the dyes' chemical structures and their EBEs, we divided each dye's frame into four sections, 
(a)

(b)

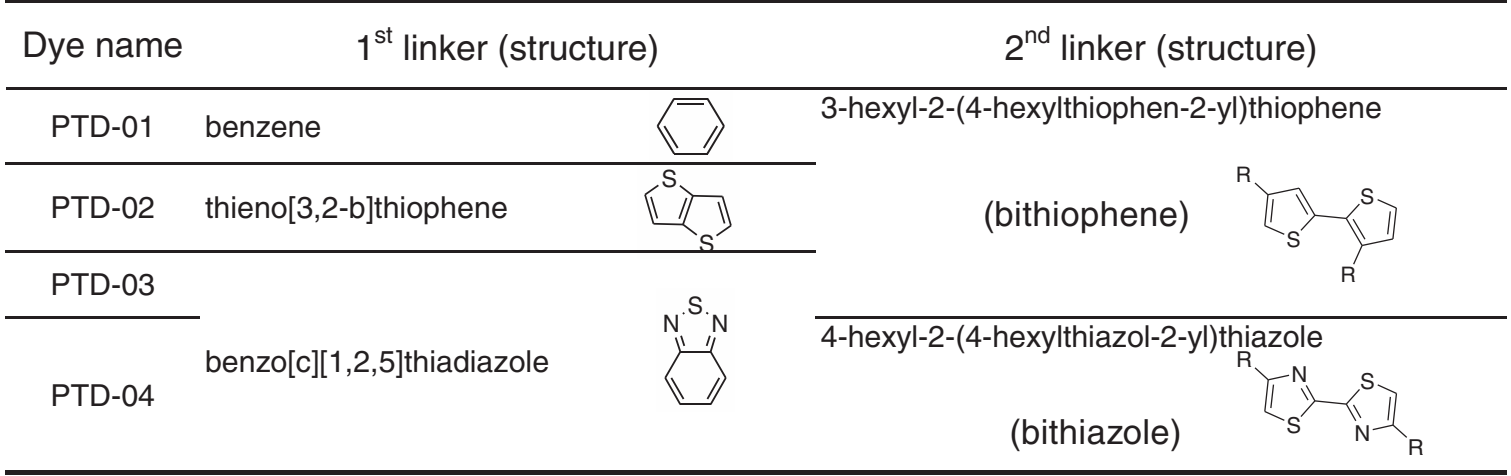

(c)

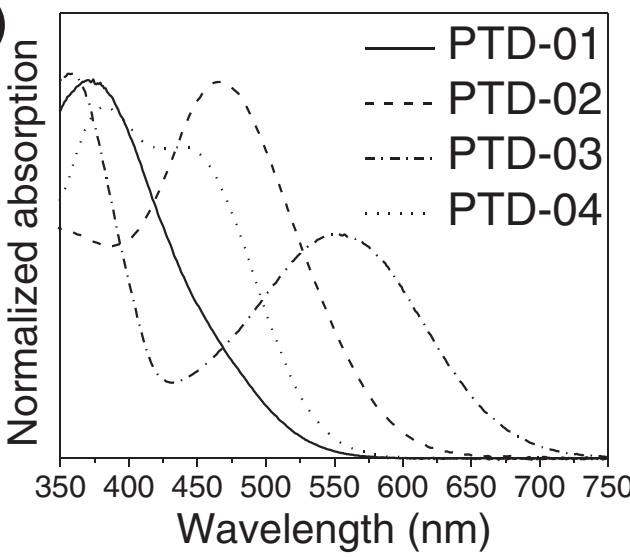

Figure 1. Chemical structures and UV-vis absorption of applied dyes. a) Prototype dye structure, b) specific dye structures (R; hexyl), and c) absorption spectra in THF.

as shown in Figure 1a. Since the characteristic properties, such as aggregation behavior, absorption range and molar extinction coefficient, ${ }^{[27,28]}$ strongly depend on the chemical structure, we fixed triphenylamine as an electron donor and cyanoacrylic acid to anchor the dyes to the semiconducting $\mathrm{TiO}_{2}$ in this study. Detailed synthetic procedures for these designed dyes are illustrated in the Supporting Information. The EBE of each dye was varied by changing the 1 st and 2 nd linkers (Figure $1 \mathrm{~b}$ ), and the calculated EBEs are summarized in Table 1. First, benzene and thieno[3,2,b]thiophene (PTD-01 and PTD-02) were selected as the first linker to compare the relationship between the dye's EBE and the photocurrent generation. Since the EBE is affected by the geometry of the conjugated molecule, ${ }^{[29]}$ benzene and

thieno[3,2,b]thiophene provide different conjugated dimensions (length and width, assuming an approximately oval shape for the dye), which results in distinctive EBEs both from PTD-01 $(0.224 \mathrm{eV})$ and PTD-02 (0.302 eV). PTD-02 shows a more redshifted absorption maximum (460 nm) than PTD-01 (375 nm) in Figure 1c, because thieno[3,2,b]thiophene has more $\pi$ electrons and gives better chain planarization than benzene. ${ }^{[30,31]}$ Next, the benzo[c][1,2,5]thiadiazole moiety (PTD-03 and PTD-04) was chosen to investigate the effect of an electron acceptor. As shown in Figure 1c, PTD-03 exhibits a bimodal and strongly red-shifted absorption compared with PTD-01 and PTD-02 because of the intramolecular charge transfer (CT) driven by the interaction between the strong electron-donating parts (triphenylamine and

Table 1. Summary of the DSSC device performance and the optical/electrical properties of the PTD series.

\begin{tabular}{|c|c|c|c|c|c|c|c|c|c|}
\hline Sample & $\begin{array}{c}J_{\mathrm{sc}} \\
{\left[\mathrm{mA} \mathrm{cm}^{-2}\right]}\end{array}$ & $\begin{array}{l}V_{o c} \\
{[V]}\end{array}$ & $\begin{array}{l}\mathrm{FF} \\
{[\%]}\end{array}$ & $\begin{array}{l}\text { PCE } \\
{[\%]}\end{array}$ & $\begin{array}{c}\text { Photon flux } \\
\text { absorption [\%] }\end{array}$ & $\begin{array}{l}\mathrm{EBE} \\
{[\mathrm{eV}]}\end{array}$ & $\begin{array}{c}E_{\text {redox }}{ }^{\text {a) }} \\
{[\mathrm{V}]}\end{array}$ & $\begin{array}{c}\left.E_{0-0}{ }^{b}\right) \\
{[V]}\end{array}$ & $\begin{array}{c}E_{\text {LUMO }}{ }^{c)} \\
{[\mathrm{V}]}\end{array}$ \\
\hline PTD-01 & 7.56 & 0.79 & 70.2 & 4.17 & 13.2 & 0.224 & 1.06 & 2.54 & -1.48 \\
\hline PTD-02 & 8.96 & 0.73 & 63.9 & 4.10 & 18.4 & 0.302 & 1.07 & 2.43 & -1.36 \\
\hline PTD-03 & 0.87 & 0.60 & 71.9 & 0.37 & 24.9 & 0.297 & 1.08 & 2.58 & -1.50 \\
\hline PTD-04 & - & - & - & - & 15.7 & 0.400 & 1.14 & 2.36 & -1.22 \\
\hline
\end{tabular}

a) The $E_{\text {redox }}$ potentials were measured on $\mathrm{TiO}_{2}$ under a scan rate of $50 \mathrm{mV} \mathrm{s}^{-1}$ (versus normal hydrogen electrode $(\mathrm{NHE})$ ) in $\mathrm{CH}_{3} \mathrm{CN}_{\text {with }} 0.1 \mathrm{M}\left(\mathrm{n}-\mathrm{C}_{4} \mathrm{H}_{9}\right){ }_{4} \mathrm{NPF}_{6}$; b) $E_{0-0}$ was determined from the intersection of the absorption and the emission spectra (Figure S1, Supporting Information) in THF; ${ }^{c} E_{\mathrm{LUMO}}$ was directly calculated by $E_{\text {redox }}-E_{0-0}$. 

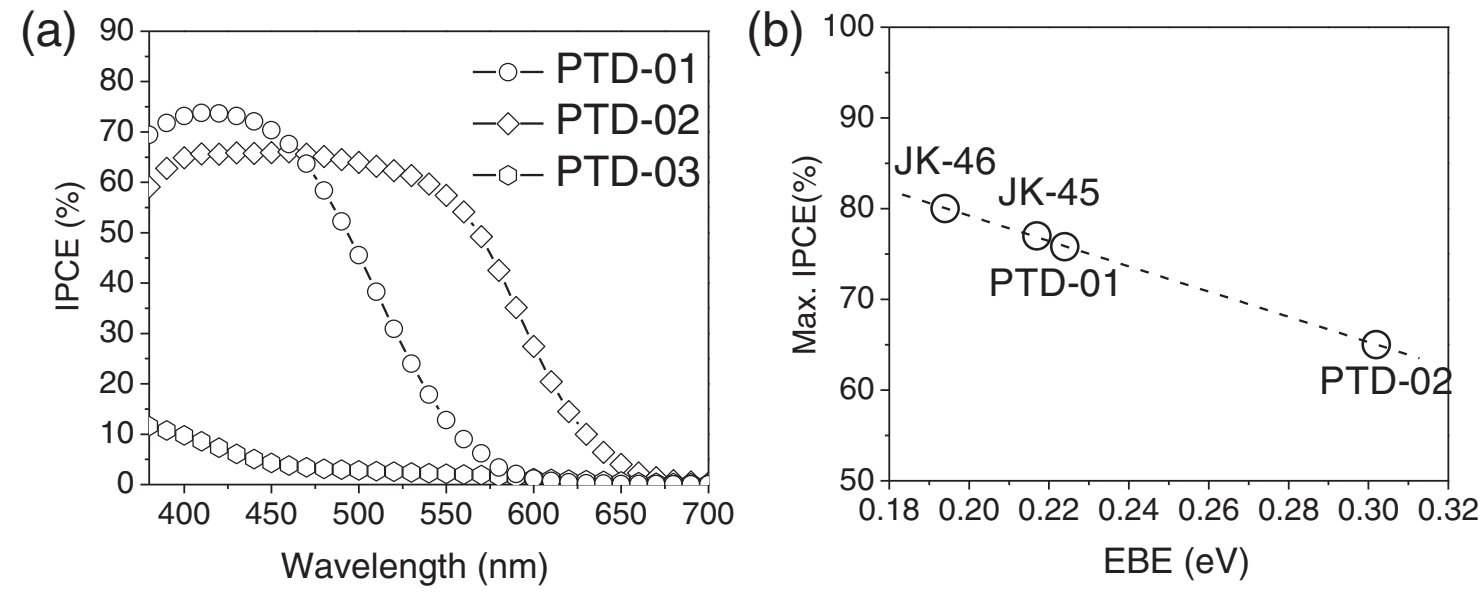

Figure 2. a) Obtained IPCE with PTD series and b) correlation between EBE and IPCE at dye's maximum absorption region.

bithiophene) and the strong electron-accepting benzo[c][1,2,5] thiadiazole. ${ }^{[32]}$ To further investigate the intramolecular CT effect on the photocurrent generation, we replaced the second linker, bithiophene, of PTD-03 with bithiazole (PTD-04). Because bithiazole is not a good electron-donating molecule, it minimizes the intramolecular CT by acting as a buffer between the electrondonating triphenylamine and the electron-accepting benzo[c] $[1,2,5]$ thiadiazole in PTD-04. In the absorption spectrum of the PTD-04 shown in Figure 1c, the bimodal absorption mostly disappears as a result of suppressing the intramolecular CT, which clearly confirms the origin of this distribution.

First, we compare the EBEs and the incident photon-to-current conversion efficiency (IPCE) of PTD-01 and PTD-02, both of which do not have an electron acceptor in their framework. In this study, a transparent semiconducting $\mathrm{TiO}_{2}$ layer (haze $35 \%$ at $800 \mathrm{~nm}, 15 \mu \mathrm{m})$ without a scattering layer was applied to compare each dye's first-hand absorption effect on the photocurrent generation. The IPCE represents the degree of energy conversion of an incident photon to current via the dissociation of a bound hole/electron pair (exciton). Therefore it should be inversely proportional to the EBE. As shown in Figure 2a and Table 1, PTD01, with its lower EBE, has indeed a higher maximum IPCE (about 76\%) than PTD-02 (about 65\%). Interestingly, the maximum IPCE exhibits a descending linear correlation with the EBEs of the PTD-01 and PTD-02. To rationalize this relation, we also calculated the EBEs of some reported organic dyes, ${ }^{[20]} \mathrm{JK}-45$ $(0.217 \mathrm{eV} / 77 \%)$ and JK-46 (0.194 eV/80\%), and plotted them with PTD-01 and PTD-02 in Figure 2b. The reference dyes also do not contain any electron acceptor in the middle of the dye framework. As shown in Figure 2b, all of the dyes share the descending linear relationship between the maximum IPCE and the EBE. Since the IPCE is the product of the absorption, the quantum yield (QY) and the collection efficiency, this plot also reveals the correlation between EBE and QY. A DSSC device adopts a thick photosensitizing layer (haze 35\% at $800 \mathrm{~nm}, 15 \mu \mathrm{m}$ ), resulting in absorption saturation around each dye's maximum absorption wavelength. Thus, the plateau region around the maximum IPCE always coincides well with each dye's maximum absorption region. Assuming that the collection efficiency is similar under the same fabrication and measurement conditions of the DSSC devices, the maximum IPCE value can be directly related to the QY of the applied organic dye.

When one considers the extinction coefficient (Figure 3a), the photon-flux absorption (Figure $3 \mathrm{~b}$ and Table 1 ) of PTD-01 and
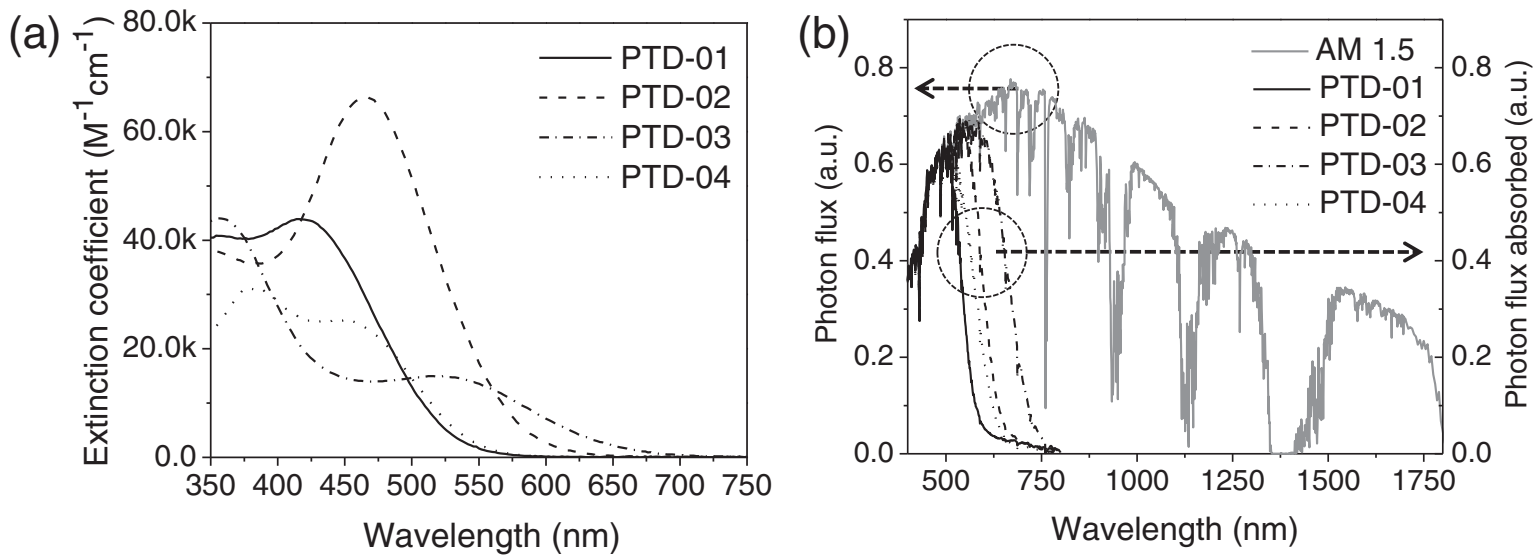

Figure 3. a) Molar extinction coefficient of tested PTD series and b) photon-flux absorption of each PTD dye from the transmittance of the DSSC device. 
PTD-02 and the short-circuit current, $J_{\mathrm{sc}}$, (Table 1) all together, it becomes very clear that PTD-01 has a higher QY in light-toelectric energy conversion than PTD-02. PTD-02 shows over $40 \%$ more photon-flux absorption and a greater than $50 \%$ increase in the molar absorption coefficient at its maximum absorption region. The more efficiently absorbed photons of PTD-02, however, are not efficiently converted to electric energy, producing $J_{\text {sc }}$ enhanced by only $20 \%$ compared with PTD-01. Therefore, PTD-01 is superior to PTD-02 in terms of energy conversion efficiency, mostly due to its lower EBE, even though PTD-02 has a comparably better absorption throughout the photon-flux range, which is helpful for collecting the incident solar spectrum. Based on this result, we conclude that the EBE is one of the most-critical factors in improving the energy conversion efficiency, and that the EBE should be considered during the molecular design of an efficient photosensitizing dye.

In comparing PTD-03 and PTD-04, which have electronwithdrawing benzo[c] $[1,2,5]$ thiadiazole in their chemical structure, a similar trend is observed (i.e., the dye with higher EBE (PTD-04) exhibits a poorer energy conversion efficiency). However, the $J_{\mathrm{sc}}$ levels they generate are too low to be compared with PTD-01 and PTD-02, indicating that the EBE factor cannot solely explain their photocurrent-generation properties. For example, PTD-02 and PTD-03 have similar EBE levels, but they exhibit completely different photocurrent-generation behaviors. Considering the photon-flux absorption, PTD-03 is likely to generate $35 \%$ more photocurrent, but it actually exhibits a much smaller $J_{\mathrm{sc}}$ compared with that of PTD-02. In addition, the absorption of PTD-03 around $550 \mathrm{~nm}$ (induced by the intramolecular CT) barely contributes to any photocurrent generation, as shown in Figure 2a. Furthermore, PTD-04, containing both an electron-withdrawing moiety and a higher EBE, did not function as a photosensitizing dye in the DSSC device, even though its energy levels had no critical problems for device operation with $\mathrm{TiO}_{2}$ and the iodine base electrolyte (Table 1). To investigate why the electron-deficient moiety in the middle of the organic-dye framework resulted in a smaller $J_{\text {sc }}$ (via the extremely low IPCE seen in Figure 2a), the dyes' molecular configurations were calculated and further optimized within the DFT framework. As shown in Figure 4, the electron density in the highest occupied molecular orbital (HOMO) state of the dyes is mostly localized around the electron-donating triphenylamine groups. However, in the lowest unoccupied molecular orbital (LUMO) state, the electrons are localized near the electron-withdrawing anchor group (cyanoacetic acid). The electron distributions within the LUMO orbitals on the anchor groups in the PTD-03 and PTD-04 are spatially less dense than those in the PTD-01 and PTD-02. Instead, the electron density around the electron-withdrawing benzo[c] $[1,2,5]$ thiadiazole seems to be relatively strengthened, indicating that the electron can be confined by a strong electron-withdrawing group. This may cause a smaller electronic coupling $(V)$ between the dyes and the $\mathrm{TiO}_{2}$, since it has been reported that the high electron density near the anchor group in the LUMO state relates to a high $J_{\mathrm{sc}}{ }^{[33]}$ According to the Marcus electron-transfer model, ${ }^{[34]}$ the electron-hopping rate $\left(k_{\text {et }}\right)$ is proportional to $V^{2}$. Thus, the injection of electrons from the PTD-03 and PTD-04 to the $\mathrm{TiO}_{2}$ will be less efficient than from the PTD-01 and PTD-02, producing smaller photocurrents in the PTD-03 and PTD-04. The reason that PTD-04 does not act as a photosensitizer in the

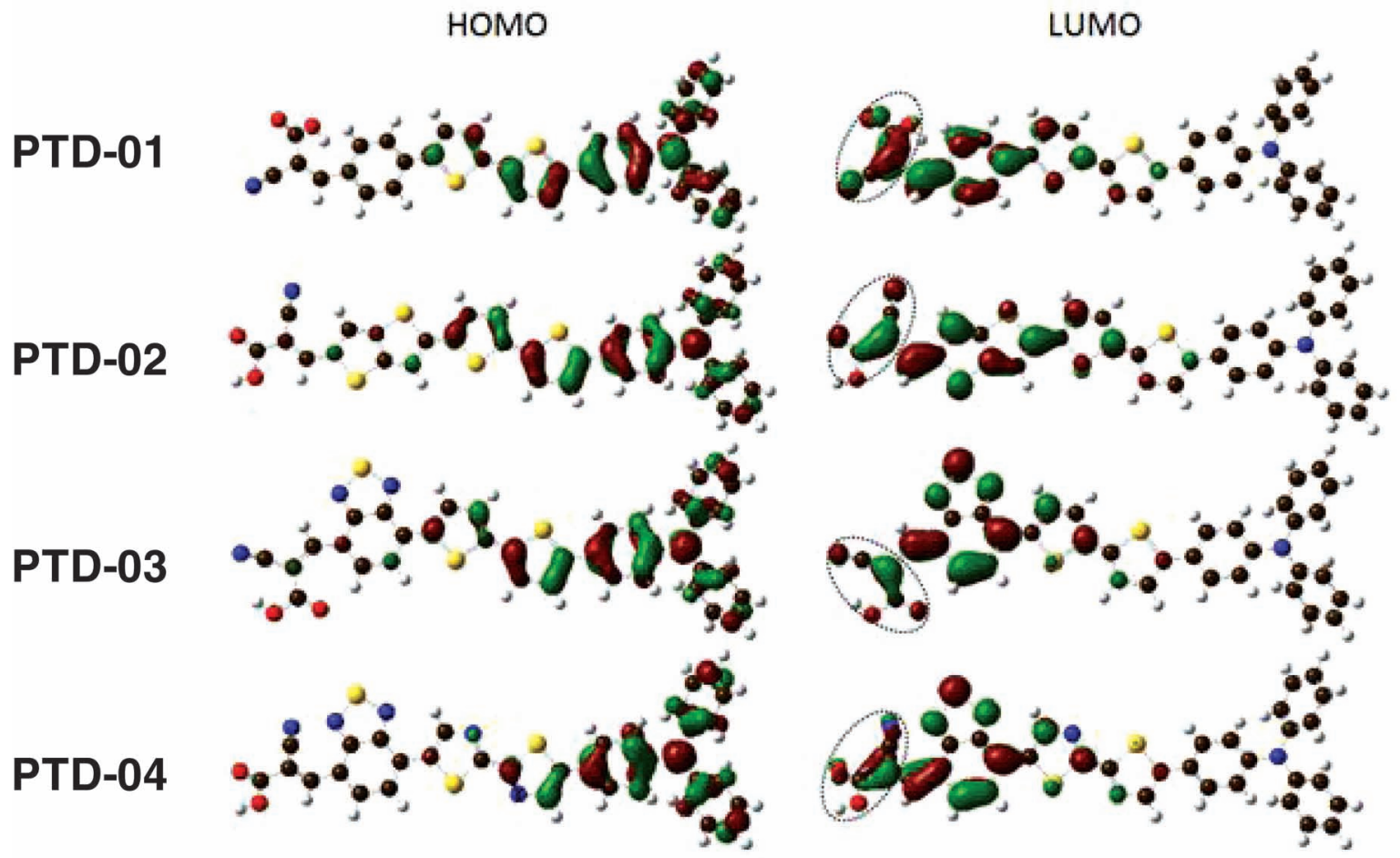

Figure 4. Electron-density surfaces (isovalue $=0.035$ ) of the HOMO and LUMO of the PTD series. The anchor groups of the dyes are inside the ovals. 
(a)

(b)

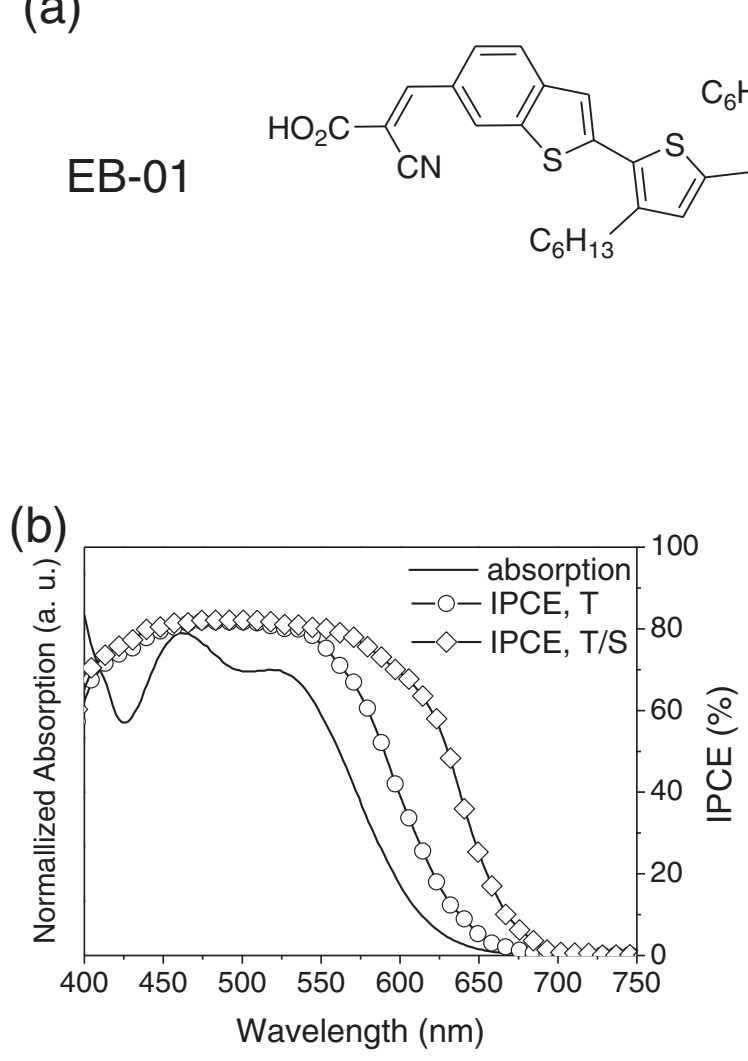

(c)<smiles>CC1(C)c2ccccc2-c2ccc(N(c3ccc4c(c3)C(C)(C)c3ccccc3-4)c3ccc4ccsc4c3)cc21</smiles>

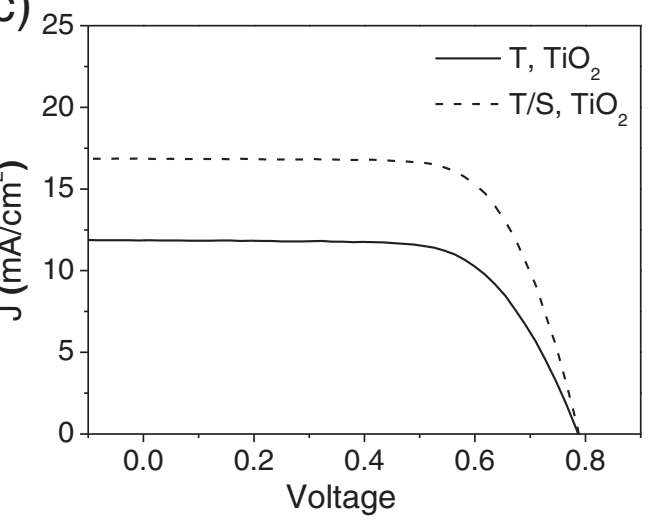

Figure 5. a) The chemical structure of EB-01, b) absorption (in THF) and IPCE spectra, and c) obtained device performance.

DSSC is likely three-fold. First, it contains the strongly electronwithdrawing benzo[c] $[1,2,5]$-thiadiazole moiety, which produces a weaker electronic coupling of the PTD-04 with the $\mathrm{TiO}_{2}$ electrode than for PTD-01 and PTD-02. Second, under AM 1.5 conditions, PTD-04 can only absorb $15.7 \%$ of the photon flux, while PTD-03 can absorb 24.9\%. Finally, the exciton binding energy of PTD-04 is larger than that of PTD-03, which lowers the charge separation efficiency. The combination of each of these factors detracts from the performance of PTD-04 in this type of photovoltaic device.

These results provide a molecular design principle for organic dyes to achieve better photocurrent-generation behavior in DSSCs. Accordingly, organic dyes for DSSC applications should be engineered so that the EBE is minimized and a strong electron acceptor in the middle of the dye frame should be avoided. In addition, their absorption spectrum should be adjusted to the photon flux. As a proof of concept, a novel organic dye, EB-01, shown in Figure 5a, was designed, based on the conclusions from our prototype PTD series dyes, and its photosensitizing properties were investigated. The two peripheral phenyl rings of the triphenylamine of the prototype dyes were replaced with the larger fluorine, and the inner phenyl groups in the PTD-01 were substituted with a longer benzene derivative (benzothiophene). These modifications gave the dye a longer conjugation and more spatial distance for electron distribution between the LUMO and HOMO levels, lowering the EBE. The EBE of EB-01 is $0.180 \mathrm{eV}$, which produces a dramatically enhanced maximum IPCE (over $81 \%$ ). We obtained over
$6 \%$ power conversion efficiency (PCE) with a high current density $\left(U_{\mathrm{sc}}=11.85 \mathrm{~mA} \mathrm{~cm}{ }^{-2}\right)$ from the DSSC device made with EB-01 and a transparent $\mathrm{TiO}_{2}$ layer (in Figure 5c, T, $\mathrm{TiO}_{2}$ ). In order to entrap the incident light more efficiently for a highperformance DSSC, a scattering $\mathrm{TiO}_{2}$ layer $(\approx 4 \mu \mathrm{m})$ was applied and the device showed a largely improved 9.18\% PCE, mostly due to the enhanced $J_{\mathrm{sc}}\left(16.86 \mathrm{~mA} \mathrm{~cm}^{-2}\right)$ (Figure $\left.5 \mathrm{c}, \mathrm{T} / \mathrm{S}, \mathrm{TiO}_{2}\right)$. Over $9.0 \%$ PCE is rarely reported from pure organic photosensitizers in DSSC devices. ${ }^{[35,36]}$ This outstanding performance of EB-01 can be ascribed to its lower EBE for an efficient lightto-electric energy conversion and to its somewhat broadened absorption characteristics for better harvesting of the solar spectrum.

\section{Conclusions}

In summary, we systematically investigated the influence of the chemical structure of organic dyes on the EBE and efficiency of the dyes as photosensitizers for DSSCs. The photocurrent generation efficiency of the synthesized dyes strongly depends on their EBEs. Dyes with a lower EBE exhibit better efficiency in generating current from the absorbed light, which demonstrates an inverse relationship between the EBE and the maximum IPCE of the dyes in DSSC devices. When the electron-withdrawing moiety, benzo[c][1,2,5]-thiadiazole, was introduced into the dye structure, it impaired the photocurrent generation significantly, because the electron-withdrawing 
moiety pulls electrons strongly, weakening the electron coupling between the dyes and the $\mathrm{TiO}_{2}$ and causing an adverse effect on charge transport. From the results for our prototype dyes, we derived dye-design principles for highly efficient photosensitizers in DSSCs. The novel organic dye, EB-01, developed on these principles, shows an excellent light-to-electric energy conversion efficiency, judging from its maximum IPCE, and exhibits an outstanding PCE of over $9 \%$.

\section{Experimental Section}

Molecular Geometry Calculation: Electronic structure calculations and spatial relaxation of the molecules were performed using Gaussian03..$^{[37]}$ Preoptimizations of the molecules were carried out using the AM1 semiempirical quantum chemistry model. ${ }^{[38]}$ The resulting molecular configurations were then further optimized in the density functional theory (DFT) framework. B3LYP was used as the exchange-correlation functional, which is a Hartree-Fock DFT hybrid where the exchange energy is explicitly calculated using the Hartree-Fock approach. ${ }^{[39]}$ The molecular geometries were optimized in the Cartesian coordinate system without any symmetry (maximum degrees of freedom) using the 6-31C* contracted Gaussian basis set with polarization functions. ${ }^{[40,41]}$

Exciton Binding Energy Calculation: EBE is directly related to the charge separation in excitonic solar cells, and hence, it is an important factor for the efficiency of the cells. ${ }^{[34]}$ The exciton binding energy can be viewed as the difference between the electronic and optical bandgap energies. ${ }^{[42]}$ For small molecules with localized wavefunctions, the electronic bandgap is approximated as the energy difference between the HOMO and LUMO levels, while the optical gap is taken to be the first excitation energy. ${ }^{[43]}$ The calculations of the excitation energy were performed using time-dependent density functional theory (TDDFT) techniques at the same approximation level as was used for the molecular structure optimizations. ${ }^{[44]}$

DSSC Device Fabrication: After cleaning, a fluorine-doped tin oxide (FTO) glass plate was immersed in aqueous $40 \times 10^{-3} \mathrm{M} \mathrm{TiCl}_{4}$ at $70^{\circ} \mathrm{C}$ for $30 \mathrm{~min}$ and washed with deionized water and ethanol. Nanocrystalline $\mathrm{TiO}_{2}$ paste was coated on top of the FTO glass by means of the doctor-blade method, followed by sintering at $500{ }^{\circ} \mathrm{C}$ for $20 \mathrm{~min}$. The obtained transparent $\mathrm{TiO}_{2}$ layer was measured with a spectrometer and a surface profiler (haze $35 \%$ at $800 \mathrm{~nm}, 15 \mu \mathrm{m}$ ). The $\mathrm{TiO}_{2}$ electrodes were immersed into each dye solution $\left(0.5 \times 10^{-3} \mathrm{M}\right.$ in a mixture of THF and tert-butyl alcohol $(\mathrm{v} / \mathrm{v} 8 / 2)$, and kept at room temperature for $24 \mathrm{~h}$ under dark conditions. Counterelectrodes were prepared by coating a drop of $\mathrm{H}_{2} \mathrm{PtCl}_{6}$ solution on the FTO glass and heating at $400{ }^{\circ} \mathrm{C}$ for $15 \mathrm{~min}$. The dye-adsorbed $\mathrm{TiO}_{2}$ electrode and $\mathrm{Pt}$ counterelectrode were assembled and sealed with an ionomer film under a hot-press. A drop of the electrolyte was filled by means of vacuum backfilling and finally, the hole was sealed with the ionomer film. The electrolyte was made with I-propyl-3-methylimidazolium iodide (PMII) $(0.7 \mathrm{M})$, iodine $\left(\mathrm{I}_{2}\right)(0.03 \mathrm{M})$, guanidiumthiocyanate $(\mathrm{CSCN})(0.05 \mathrm{M})$ and 4-tert-butylpyridine (TBP) (0.5 M) in 3-methoxypropionitrile (MPN) solvent.

\section{Supporting Information}

Supporting Information is available from the Wiley Online Library or from the author.

\section{Acknowledgements}

B.-G.K. and C.-G.Z. contributed equally to this work. This research was supported as part of the Center for Solar and Thermal Energy Conversion in Complex Materials, an Energy Frontier Research Center funded by the US Department of Energy, Office of Science, Office of Basic Energy Sciences under Award Number (DE-SC0000957).

Received: August 20, 2011

Revised: October 24, 2011

Published online: February 6, 2012

[1] M. K. Nazeeruddin, F. De Angelis, S. Fantacci, A. Selloni, G. Viscardi, P. Liska, S. Ito, T. Bessho, M. Grätzel, J. Am. Chem. Soc. 2005, 127, 16835.

[2] B. O'Regan, M. Grätzel, Nature 1991, 353, 737.

[3] F. Gao, Y. Wang, D. Shi, J. Zhang, M. Wang, X. Jing, J. Am. Chem. Soc. 2008. 130, 10720.

[4] M. Grätzel, Prog. Photovoltaics 2006, 14, 429.

[5] M. K. Nazeeruddin, Coord. Chem. Rev. 2004, 248, 1161.

[6] N.-G. Park, M. G. Kang, K. M. Kim, K. S. Ryu, S. H. Chang, D.-K. Kim, J. Van de Lagemaat, K. D. Benkstein, A. J. Frank, Langmuir 2004, 20, 4246.

[7] T. A. Heimer, E. J. Heilweil, C. A. Bignozzi, G. J. Meyer, J. Phys. Chem. A 2000, 104, 4256.

[8] A. Hagfeldt, M. Grätzel, Acc. Chem. Res. 2000, 33, 269.

[9] M. Ye, X. Xin, C. Lin, Z. Lin, Nano Lett. 2011, 11, 3214.

[10] J. Wang, Z. Lin, Chem. Mater. 2010, 22, 579.

[11] H. Tian, X. Yang, R. Chen, R. Zhang, A. Hagfeldt, L. Sun, J. Phys. Chem. C 2008, 112, 11023.

[12] M. Liang, W. Xu, F. Cai, P. Chen, B. Peng, J. Chen, Z. Li, J. Phys. Chem. C 2007, 111, 4465.

[13] W. Zeng, Y. Cao, Y. Bai, Y. Wang, Y. Shi, M. Zhang, F. Wang, C. Pan, P. Wang, Chem. Mater. 2010, 22, 1915.

[14] K. Hara, Z. S. Wang, T. Sato, A. Furube, R. Katoh, H. Sugihara, Y. Dan-oh, C. Kasada, A. Shinpo, S. Suga, J. Phys. Chem. B 2005, 109, 15476

[15] Z.-S. Wang, Y. Cui, K. Hara, Y. Dan-oh, C. Kasada, A. Shinpo, Adv. Mater. 2007, 19, 1138.

[16] K. Sayama, K. Hara, N. Mori, M. Satsuki, S. Suga, S. Tsukagoshi, Y. Abe, H. Sugihara, H. Arakawa, Chem. Commun. 2000, 1173.

[17] M. O. Lenz, J. Wachtveitl, J. Phys. Chem. C 2008, 112, 11973.

[18] T. Horiuchi, H. Miura, K. Sumioka, S. Uchida, J. Am. Chem. Soc. 2004, 126, 12218

[19] S. Ito, S. M. Zakeeruddin, R. Humphry-Baker, P. Liska, R. Charvet, P. Comte, M. K. Nazeeruddin, P. Péchy, M. Takata, H. Miura, S. Uchida, M. Grätzel, Adv. Mater. 2006, 18, 1202.

[20] H. Choi, C. Baik, S. O. Kang, J. Ko, M.-S. Kang, M. K. Nazeeruddin, M. Grätzel, Angew. Chem. Int. Ed. 2008, 47, 327.

[21] C.-H. Chen, Y.-C. Hsu, H.-H. Chou, K. R. J. Thomas, J. T. Lin C.-P. Hsu, Chem. Eur. J. 2010, 16, 3184.

[22] K. Hara, Z.-S. Wang, Y. Cui, A. Furube, N. Koumura, Energy Environ. Sci. 2009, 2, 1109.

[23] Z.-S. Wang, N. Koumura, Y. Cui, M. Takahashi, H. Sekiguchi, A. Mori, T. Kubo, A. Furube, K. Hara, Chem. Mater. 2008, 20, 3993.

[24] O. Kohle, M. Grätzel, A. F. Meyer, T. B. Meyer, Adv. Mater. 1997, 9, 904.

[25] D. Liu, R. W. Fessenden, G. L. Hug, P. V. Kamat, J. Phys. Chem. B 1997, 101, 2583.

[26] K. Hara, T. Sato, R. Katoh, A. Furube, Y. Ohga, A. Shinpo, S. Suga, K. Sayama, H. Sugihara, H. Arakawa, J. Phys. Chem. B 2003, 107, 597.

[27] M. Pastore, F. D. Angelis, ACS Nano 2010, 4, 556.

[28] H. Chen, H. Huang, X. Huang, J. N. Clifford, A. Forneli, E. Palomares, X. Zheng, L. Zheng, X. Wang, P. Shen, B. Zhao, S. Tan, J. Phys. Chem. C 2010, 114, 3280

[29] M. Knupfer, Appl. Phys. A 2003, 77, 623. 
[30] G. Li, K.-J. Jiang, Y.-F. Li, S.-L. Li, L.-M. Yang, J. Phys. Chem. C 2008, $112,11591$.

[31] S. Hwang, J. H. Lee, C. Park, H. Lee, C. Kim, C. Park, M.-H. Lee, W. Lee, J. Park, K. Kim, N.-G. Park, C. Kim, Chem. Commun. 2007, 4887.

[32] S.-L. Wang, T.-I. Ho, J. Photochem. Photobiol. A 2000, 135, 119.

[33] R. Jose, A. Kumar, V. Thavasi, K. Fujihara, S. Uchida, S. Ramakrishna, Appl. Phys. Lett. 2008, 93, 023125.

[34] R. A. Marcus, N. Sutin, Biochim. Biophys. Acta 1985, 811, 265.

[35] S. Ito, H. Miura, S. Uchida, M. Takata, K. Sumioka, P. Liska, P. Comte, P. Pechy, M. Grätzel, Chem. Commun. 2008, 5194.

[36] G. Zhang, H. Bala, Y. Cheng, D. Shi, X. Lv, Q. Yu, P. Wang, Chem. Commun. 2009, 2198.

[37] M. J. Frisch, G. W. Trucks, H. B. Schlegel, G. E. Scuseria, M. A. Robb, J. R. Cheeseman Jr., J. A. Montgomery, T. Vreven, K. N. Kudin, J. C. Burant, J. M. Millam, S. S. Iyengar, J. Tomasi, V. Barone, B. Mennucci, M. Cossi, G. Scalmani, N. Rega, G. A. Petersson, H. Nakatsuji, M. Hada, M. Ehara, K. Toyota, R. Fukuda, J. Hasegawa, M. Ishida, T. Nakajima, Y. Honda, O. Kitao, H. Nakai, M. Klene, X. Li, J. E. Knox, H. P. Hratchian, J. B. Cross, V. Bakken,
C. Adamo, J. Jaramillo, R. Gomperts, R. E. Stratmann, O. Yazyev, A. J. Austin, R. Cammi, C. Pomelli, J. W. Ochterski, P. Y. Ayala, K. Morokuma, G. A. Voth, P. Salvador, J. J. Dannenberg, V. G. Zakrzewski, S. Dapprich, A. D. Daniels, M. C. Strain, O. Farkas, D. K. Malick, A. D. Rabuck, K. Raghavachari, J. B. Foresman, J. V. Ortiz, Q. Cui, A. G. Baboul, S. Clifford, J. Cioslowski, B. B. Stefanov, G. Liu, A. Liashenko, P. Piskorz, I. Komaromi, R. L. Martin, D. J. Fox, T. Keith, M. A. Al-Laham, C. Y. Peng, A. Nanayakkara, M. Challacombe, P. M. W. Gill, B. Johnson, W. Chen, M. W. Wong, C. Gonzalez, J. A. Pople, Gaussian 03, Revision C. 02, Gaussian, Inc., Wallingford CT, 2004.

[38] J. J. P. Stewart, J. Comput. Chem. 1989, 10, 209.

[39] A. D. Becke, J. Chem. Phys. 1993, 98, 5648.

[40] M. M. Francl, W. J. Pietro, W. J. Hehre, J. S. Binkley, M. S. Gordon, D. J. Defrees, J. A. Pople, J. Chem. Phys. 1982, 77, 3654.

[41] W. J. Hehre, R. Ditchfie, J. A. Pople, J. Chem. Phys. 1972, 56, 2257.

[42] B. A. Gregg, J. Phys. Chem. B 2003, 107, 4688.

[43] G. D. Scholes, G. Rumbles, Nat. Mater. 2006, 5, 683.

[44] C.-G. Zhen, U. Becker, J. Kieffer, J. Phys. Chem. A 2009, 113, 9707. 